\title{
EDITORIAL
}

\section{Pharmacological options for BPD prevention: steps for better clinical trial design}

\author{
Journal of Perinatology (2014) 34, 653-654; \\ doi:10.1038/jp.2014.130
}

The incidence of bronchopulmonary dysplasia (BPD) has remained relatively unchanged over the past 20 years despite intensive efforts to prevent this important complication of extreme prematurity. Approximately $40 \%$ of infants born at less than 29 weeks gestation are diagnosed with BPD, which is defined as oxygen supplementation at 36 weeks postmenstrual age. ${ }^{1}$ Although genetic susceptibility may account for $35-65 \%$ risk for $\mathrm{BPD}^{2}$ center-based incidence varies considerably, ${ }^{3}$ suggesting that clinical practices are modifiable risk factors.

Developing a pharmacological approach to BPD prevention has been a major focus of neonatal research. In this issue of the Journal of Perinatology, Beam et al., ${ }^{4}$ summarize a systematic review encompassing studies published over more than a 20-year period of pharmacological interventions to prevent BPD in at-risk preterm infants. The authors identified 47 randomized controlled trials (RCTs) and 19 early-phase trials that enrolled more than 20000 infants to determine whether 21 drugs prevent BPD. In their analyses, only five drugs (vitamin A, dexamethasone, caffeine, inositol and clarithromycin) from 13 trials were found effective in reducing BPD. Two of the drugs (inositol and clarithromycin) were single-center RCTs and their efficacy has not been confirmed. The authors explored possible explanations for the disappointing results for such extensive efforts.

\section{WRONG DRUG OR WRONG DOSE?}

Only seven (16\%) RCTs included in the systematic review were preceded by early-phase studies evaluating pharmacokinetics and/or safety and efficacy. Furthermore, despite the large number of RCTs to prevent BPD, no drugs are currently FDA-labeled for the prevention of BPD. This underscores a larger concern for drug exposures in the neonatal intensive care unit. More than $90 \%$ of drugs used in the neonatal intensive care unit are off-label; ${ }^{5}$ that is, not FDA-approved for the prescribed indication, with infants exposed to as many as 60 separate drugs during the course of their hospitalization to the neonatal intensive care unit. ${ }^{6}$ The federal government, through legislative actions and initiatives of the Food and Drug Administration and National Institutes of Health, has taken important steps in the last two decades to improve the drug development process in neonates and children. The FDA Modernization Act, Best Pharmaceuticals for Children Act and the Pediatric Research Equity Act have been credited with over 500 pediatric labeling changes, but only one involved preterm infants (INOmax). ${ }^{7,8}$ There are certainly challenges to conducting the pharmacokinetic (PK) and safety studies required by the FDA for label change in the preterm population, but the consequences of testing the wrong dose are either that the drug will be ineffective or that the infants are exposed to unnecessary side effects. To increase the chance of success of Phase III RCTs and to limit exposure of our vulnerable research subjects to unsafe or ineffective dose regimens, we need to first conduct studies to understand a drug's pharmacokinetics in the preterm population.

Some of the challenges, their implications and potential solutions are outlined in Table 1 . Since infants $\leqslant 28$ weeks gestation are at greatest risk for BPD, multi-center collaborations are required for early-phase studies to accelerate the dose optimization and safety evaluations before proceeding to Phase III RCTs. Although there are ethical concerns for obtaining consent from overwhelmed, stressed parents and exposure of a vulnerable population to new therapies (or current unproven therapies), neonatal drug research is scientifically and ethically essential., ${ }^{9,10}$ Blood sampling for PK studies is limited in preterm infants, but strategies using sparse sampling, use of residual blood samples from clinical specimens, population PK simulations/modeling and analytical methods for drug detection in $<100 \mu \mathrm{l}$ of blood have been successfully employed for this purpose in this population. ${ }^{7}$ There are developmental and postnatal age-dependent differences in drug absorption, distribution, metabolism and excretion between preterm and term infants as well as older children due to immaturity of multiple organ systems, differences of body composition and rapid postnatal adaptations. Therefore, extrapolating dosing from adults or older children may be inadequate without taking these differences into account. Moreover, neonatal PK studies need to be stratified by gestational age rather than birthweight. Multidisciplinary collaborations of developmental lung biologists to identify therapeutic targets and conduct pre-clinical studies, neonatal pharmacologists to assist in PK/pharmacodynamic study design and analysis, and neonatologists with clinical trial expertise, supported by funding and regulatory agencies, should be able to better address drug trial design for future studies to prevent BPD., ${ }^{6,11}$

\section{WRONG END POINT?}

Over the course of the 22 years included in the systematic review, the definition of BPD evolved. Thirty-one (66\%) studies evaluated a combined outcome of death and BPD. In the majority of the studies, the BPD definition used was oxygen supplementation at 36 weeks postmenstrual age $(N=22,71 \%)$, while older studies used the definition of oxygen supplementation at 28 days $(N=14$, $45 \%$ ) and four studies used both definitions. Only two studies used the physiological BPD at 36 weeks outcome determined by a room air challenge. Although not a focus of this systematic review, few of the drugs studied for the prevention of BPD have been studied for their effects on later pulmonary health. Since children born prematurely with a history of BPD are at increased risk for respiratory illnesses, need for hospitalization, respiratory medications and lung function abnormalities during the first year of life, at school age and beyond, ${ }^{12-14}$ it may be more important to assess drug efficacy to prevent these later complications. Compared to placebo, vitamin A reduced the incidence of BPD and death in the neonatal period, ${ }^{15}$ but did not reduce supplemental oxygen use post discharge, or respiratory hospitalizations or medication use at 18-22 months corrected age. ${ }^{16}$ In contrast, intratracheal CuZn superoxide dismutase did not prevent BPD at 28 days or 36 weeks postmenstrual age, but at 1 year corrected the treatment group had less frequent wheezing, respiratory illness requiring medications and hospitalizations than the placebo group. ${ }^{17}$ These studies highlight the importance of longitudinal pulmonary assessments of infants enrolled in neonatal trials to prevent BPD and the need for discovery of better 
Table 1. Challenges, implications and potential solutions for clinical trials to prevent BPD

\begin{tabular}{|c|c|c|}
\hline Factors & Implications & Potential solutions \\
\hline \multirow{4}{*}{$\begin{array}{l}\mathrm{GA} \leqslant 28 \text { weeks is the highest risk } \\
\text { factor for } \mathrm{BPD} \\
\text { Ethical and regulatory concerns in the } \\
\text { vulnerable population }\end{array}$} & $\begin{array}{l}\text { Few subjects per center } \\
\text { Competing studies }\end{array}$ & Requires multi-center collaborations \\
\hline & $\begin{array}{l}\text { Careful consideration of risk vs potential } \\
\text { benefit in study designs }\end{array}$ & Ensure risk-based protections for subjects \\
\hline & $\begin{array}{l}\text { Informed consent process that truly } \\
\text { informs the parents }\end{array}$ & Studies of parent feedback on the consent process \\
\hline & $\begin{array}{l}\text { Streamlining IRB review of multicenter } \\
\text { studies }\end{array}$ & Single IRB review for multicenter studies \\
\hline \multirow{4}{*}{$\begin{array}{l}\text { Limitations of the amount of blood for } \\
\text { PK studies } \\
\text { Immaturity of multiple organ systems }\end{array}$} & Lack of pharmacological studies to inform & Use residual clinical blood specimens \\
\hline & dosing regimens & Sparse sampling, population PK modeling \\
\hline & $\begin{array}{l}\text { Extrapolating from doses for adults and } \\
\text { older children insufficient }\end{array}$ & $\begin{array}{l}\text { Multidisciplinary collaborations of neonatologists, } \\
\text { developmental lung biologists and neonatal }\end{array}$ \\
\hline & $\begin{array}{l}\text { PK study design should be stratified by GA } \\
\text { rather than BW }\end{array}$ & $\begin{array}{l}\text { pharmacologists to improve drug selection and study } \\
\text { design }\end{array}$ \\
\hline $\begin{array}{l}\text { High mortality and multiple } \\
\text { morbidities in infants } \leqslant 28 \text { weeks }\end{array}$ & $\begin{array}{l}\text { Difficult to distinguish known morbidities } \\
\text { of prematurity from drug-related adverse } \\
\text { events }\end{array}$ & $\begin{array}{l}\text { Inclusion of survival in the composite outcome for BPD } \\
\text { Systematic approach for collection and analysis of adverse } \\
\text { events }\end{array}$ \\
\hline \multirow{4}{*}{$\begin{array}{l}\text { What is the optimal outcome of } \\
\text { interest? } \\
\text { Impact on long-term } \\
\text { neurodevelopmental outcomes }\end{array}$} & $\begin{array}{l}\text { Efficacy of drugs may not be apparent until } \\
\text { later in infancy or childhood }\end{array}$ & $\begin{array}{l}\text { Biomarkers to predict adverse pulmonary outcomes } \\
\text { Lung health outcomes assessed at } 1 \text { and } 2 \text { years of age }\end{array}$ \\
\hline & Costly to include long-term follow-up & Neurodevelopmental follow-up up to 2 years should be \\
\hline & Centers involved in clinical trials should & included in study design \\
\hline & $\begin{array}{l}\text { have prior track record for minimizing loss } \\
\text { to follow-up }\end{array}$ & Funding for this study component \\
\hline
\end{tabular}

biomarkers in the newborn period that predict later lung health outcomes.

\section{CONFLICT OF INTEREST}

The author declares no conflict of interest.

\section{ACKNOWLEDGEMENTS}

The Eunice Kennedy Shriver National Institute Of Child Health \& Human Development supported the research reported in this publication under Award Number R01HD067126.

\section{DISCLAIMER}

The content described here is solely the responsibility of the author and does not necessarily represent the official views of the National Institute of Health.

RM Viscardi

Department of Pediatrics, University of Maryland School of Medicine, Baltimore, MD, USA

E-mail: rviscard@umaryland.edu

\section{REFERENCES}

1 Stoll BJ, Hansen NI, Bell EF, Shankaran S, Laptook AR, Walsh MC et al. Neonatal outcomes of extremely preterm infants from the NICHD Neonatal Research Network. Pediatrics 2010; 126: 443-456.

2 Bhandari V, Bizzarro MJ, Shetty A, Zhong X, Page GP, Zhang $\mathrm{H}$ et al. Familial and genetic susceptibility to major neonatal morbidities in preterm twins. Pediatrics 2006; 117: 1901-1906.

3 Ambalavanan N, Walsh M, Bobashev G, Das A, Levine B, Carlo WA et al. Intercenter differences in bronchopulmonary dysplasia or death among very low birth weight infants. Pediatrics 2011; 127: e106-e116.
4 Beam KS, Aliaga S, Ahlfeld SK, Cohen-Wolkowiez M, Smith PB, Laughon MM. A systematic review of randomized controlled trials for the prevention of bronchopulmonary dysplasia in infants. J Perinatol 2014; 34: 705-710.

5 Giacoia GP, Taylor-Zapata P, Zajicek A. Drug studies in newborns: a therapeutic imperative. Clin Perinatol 2012; 39: 11-23.

6 Davis JM, Connor EM, Wood AJ. The need for rigorous evidence on medication use in preterm infants: is it time for a neonatal rule? JAMA 2012; 308: $1435-1436$.

7 Wiles JR, Vinks AA, Akinbi H. Federal legislation and the advancement of neonatal drug studies. J Pediatr 2013; 162: 12-15.

8 US Food and Drug Administration. New Pediatric labeling Information Database. http://www.accessdata.fda.gov/scripts/sda/sdNavigation.cfm?sd = labelingdatabase (accessed 26 May 2014).

9 Baer GR, Nelson RM. Ethical challenges in neonatal research: summary report of the ethics group of the newborn drug development initiative. Clin Ther 2006; 28: 1399-1407.

10 Laventhal N, Tarini BA, Lantos J. Ethical issues in neonatal and pediatric clinical trials. Pediatr Clin North Am 2012; 59: 1205-1220.

11 Turner MA. Neonatal drug development. Early Hum Dev 2011; 87: 763-768.

12 Bhandari A, McGrath-Morrow S. Long-term pulmonary outcomes of patients with bronchopulmonary dysplasia. Semin Perinatol 2013; 37: 132-137.

13 Gibson AM, Doyle LW. Respiratory outcomes for the tiniest or most immature infants. Semin Fetal Neonatal Med 2014; 19: 105-111.

14 Vom Hove M, Prenzel F, Uhlig HH, Robel-Tillig E. Pulmonary outcome in former preterm, very low birth weight children with bronchopulmonary dysplasia: a casecontrol follow-up at school age. J Pediatr 2014; 164: 40-45, e44.

15 Tyson JE, Wright LL, Oh W, Kennedy KA, Mele L, Ehrenkranz RA et al. Nationa Institute of Child Health and Human Development Neonatal Research Network. Vitamin A supplementation for extremely-low-birth-weight infants. $N$ Engl J Med 1999; 340: 1962-1968.

16 Ambalavanan N, Tyson JE, Kennedy KA, Hansen NI, Vohr BR, Wright LL et al. Vitamin A supplementation for extremely low birth weight infants: outcome at 18 to 22 months. Pediatrics 2005; 115: e249-e254.

17 Davis JM, Parad RB, Michele T, Allred E, Price A, Rosenfeld W. Pulmonary outcome at 1 year corrected age in premature infants treated at birth with recombinant human CuZn superoxide dismutase. Pediatrics 2003; 111: 469-476. 